\section{Pre-exposure to yeast protects larvae of Galleria mellonella from a subsequent lethal infection by Candida albicans and is mediated by the increased expression of antimicrobial peptides}

\author{
David Bergin ${ }^{\mathrm{a}}$, Lisa Murphy ${ }^{\mathrm{b}}$, Joanne Keenan ${ }^{\mathrm{b}}$, Martin Clynes ${ }^{\mathrm{b}}$, Kevin Kavanagh ${ }^{\mathrm{a}, *}$ \\ ${ }^{a}$ Department of Biology, Medical Mycology Unit, NICB, National University of Ireland Maynooth, Co. Kildare, Ireland \\ ${ }^{\mathrm{b}}$ National Institute for Cellular Biotechnology, Dublin City University, Glasnevin, Dublin 9, Ireland
}

Received 14 December 2005; accepted 26 March 2006

\begin{abstract}
Pre-exposure of the larvae of Galleria mellonella to Candida albicans or Saccharomyces cerevisiae protects against a subsequent infection with $10^{6} \mathrm{C}$. albicans cells. This protection can also be induced by exposing larvae to glucan or laminarin prior to the administration of the potentially lethal inoculum. Analysis of the expression of genes coding for galiomicin, a defensin in G. mellonella, a cysteine-rich antifungal peptide gallerimycin, an iron-binding protein transferrin and an inducible metalloproteinase inhibitor (IMPI) from G. mellonella demonstrated increased expression, which is at its highest after $24 \mathrm{~h}$ of the initial inoculum. Examination of the expression of proteins in the insect haemolymph using 2D electrophoresis and MALDI TOF analysis revealed an increased expression of a number of proteins associated with the insect immune response to infection $24 \mathrm{~h}$ after the initial exposure. This study demonstrates that the larvae of $G$. mellonella can withstand a lethal inoculum of $C$. albicans if pre-exposed to a non-lethal dose of yeast or polysaccharide $24 \mathrm{~h}$ previously which is mediated by increased expression of a number of antimicrobial peptides and the appearance of a number of peptides in the challenged larvae.

(C) 2006 Published by Elsevier SAS.
\end{abstract}

Keywords: Galleria mellonella; Antimicrobial proteins; Host defence; 2D gel electrophoresis; MALDI TOF analysis; Gene expression

\section{Introduction}

Insects are one of the most successful and diverse forms of animal life on Earth [1] and possess an immune system that shows strong structural and functional similarities with the ininsect's immune response involves a cellular component where haemocytes recognise and phagocytose microbes, form nodules or encapsulate foreign particles [3]. The humoral element of the immune response consists of proteins involved in clotting such as vitellogenin-like proteins that contain a cysteinerich region which is homologous to the mammalian clottable

\footnotetext{
* Corresponding author. Tel.: +3531708 3859; fax: +3531 7083845 .

E-mail address: kevin.kavanagh@nuim.ie (K. Kavanagh).
} nate immune system of mammals [2]. During an infection, the proteins of the Von Willebrand factor involved in blood clotting [2], and antimicrobial peptides (AMPs) such as defensins, which have been highly conserved through evolution [4]. AMPs are released from a range of organs and cells $[5,6]$ into the haemolymph of the insect where they diffuse to the site of infection and attack components of the bacterial or fungal cell wall [7]. Haemocytes, the fat body and the digestive tract secrete antimicrobial proteins and peptides into the insect haemolymph, which performs many functions analogous to mammalian serum $[5,6,8]$. The similarity of a range of insect immune responses with vertebrate innate immune responses to infection has been highlighted by the discovery of the Toll receptors in insects and their similarity with the toll like receptors (TLR) in mammals and 11 members of this family have been identified in humans [9]. 
RNA analysis or Reverse Transcriptase Polymerase Chain 116 Reaction (RT PCR) has been employed to quantify transcript 117 levels of specific genes. Whole RNA from adult Drosophila 118 infected with a range of microorganisms using Northern blot119 ting established that several antimicrobial peptide transcripts 120 were differentially expressed over $72 \mathrm{~h}$ depending upon the 121 microbe used in the infection study [10]. Differently, expres122 sion of transferrin [11] and a metalloproteinase inhibitor in 123 Galleria mellonella following exposure to LPS has also been 124 observed [12].

125 Mass spectrometry analysis of tryptic-digested proteins or 126 naturally occurring peptides (peptidomics) has also been 127 used to quantify the changes in protein expression and the in128 duction of novel proteins following infection [13]. Recent 129 studies have utilised two-dimensional (2D) analysis of Dro130 sophila haemolymph and Anopheles gambiae [14] and many 131 groups have reported data concerning protein expression and 132 induction in Drosophila utilising a proteomic approach 133 [15-17].

134 Given the similarities between the insect immune response 135 and the innate immune response of mammals, insects have 136 been utilised to quantify the pathogenicity of microbes and 137 to model the innate immune response without the requirement 138 of mammals [18]. Insects have been employed to assess the 139 relative pathogenicity of bacteria [19], fungi [20] and parasites 140 [21] and positive correlations with results from murine studies 141 have been demonstrated in C. albicans [22] and Pseudomonas 142 aeruginosa [23].

143 The aim of the work presented here was to establish 144 whether it was possible to induce a protective immune re145 sponse in the larvae of G. mellonella following infection 146 with a sub-lethal dose of yeast or fungal cell wall components. 147 It was our intention to establish how this protection was in148 duced in the insects and to ascertain the nature of the peptides 149 mediating the effect.

\section{Materials and methods}

\subsection{Chemicals and reagents}

All chemicals and reagents were of the highest purity and were purchased from Sigma Aldrich Chemical Company Ltd. (Dorset, UK) unless stated otherwise.

\subsection{Yeast strains and culture conditions}

C. albicans MEN (Dr. D. Kerridge, Cambridge, UK) and Saccharomyces cerevisiae YJM128 (Dr. K. Clemons, Santa Clara Valley Medical Centre, CA, USA) were used in this study. Yeast cultures were grown to the stationary phase 170 and $1 \%(\mathrm{w} / \mathrm{v})$ yeast extract (Oxoid)) in $100 \mathrm{ml}$ conical flasks 171 at $30{ }^{\circ} \mathrm{C}$ and $200 \mathrm{rpm}$ in an orbital incubator.

\subsection{Insect larvae}

Sixth instar larvae of G. mellonella (Lepidoptera: Pyralidae, the Greater Wax Moth) (Mealworm Company, Sheffield, England) were stored in wood shavings in the dark at $15{ }^{\circ} \mathrm{C}$ [20]. Larvae were inoculated as described previously [20].

\subsection{Induction of expression of immune relevant proteins of G. mellonella by $R T P C R$}

Larval RNA was extracted using TRI-reagent at 1, 4, 8, 24 and $48 \mathrm{~h}$ post-infection. RNA $(2 \mu \mathrm{g})$ was treated with DNase I prior to cDNA synthesis using the SuperScript Kit (Invitrogen) with oligo(dT) primers.

PCR amplification of target genes was performed with primers listed in Table 1 and using the following conditions: $94{ }^{\circ} \mathrm{C}$ denaturation for $5 \mathrm{~min}\left(94{ }^{\circ} \mathrm{C}\right.$ denaturation for $60 \mathrm{~s}$, $55{ }^{\circ} \mathrm{C}$ for $90 \mathrm{~s}, 68{ }^{\circ} \mathrm{C}$ extension for $\left.90 \mathrm{~s}\right) \times 26$ cycles; $68{ }^{\circ} \mathrm{C}$ extension for $10 \mathrm{~min}$. Visualisation of amplified products was performed using a Syngene Geneflash and densitometric analysis of PCR products was carried out using Genetools software. All samples were normalised to the corresponding $\beta$ actin value. The highest level of expression in a series was set to $100 \%$ and other values of that series are given as percentage relative activity [10].

\section{5. $2 \mathrm{D}$ gel electrophoretic separation of haemolymph proteins}

Iso-electric focussing (IEF) was performed with $0.3 \mathrm{mg}$ of haemolymph protein loaded on $13 \mathrm{~cm}$ IPG strips (Amersham Biosciences UK Ltd.) with $50 \mu \mathrm{A}$ per strip and using the IPGphor focusing system (Amersham Biosciences) with the following running conditions: $10 \mathrm{~h}$ at $50 \mathrm{~V}, 15 \mathrm{~min}$ at $250 \mathrm{~V}$, $5 \mathrm{~h}$ gradient at $8000 \mathrm{~V}$ and the final step was $8 \mathrm{~h}$ step and hold at $8000 \mathrm{~V}$.

After separation of proteins in the first dimension, strips were equilibrated twice for $15 \mathrm{~min}$ in equilibration buffer

Table 1

PCR primer pairs used to amplify regions of four genes involved in the immune system and a housekeeping gene

\begin{tabular}{lll}
\hline Primer name & Oligonucleotides & $\begin{array}{l}\text { Fragment size } \\
\text { (base pair (bp) }\end{array}$ \\
\hline$\beta$ actin $\mathrm{F}^{\mathrm{a}}$ & GGGACGATATGGAGAAGATCTG & 400 \\
$\beta$ actin $\mathrm{R}^{\mathrm{b}}$ & CACGCTCTGTGAGGATCTTC & \\
Transferrin F & CCCGAAGATGAACGATCAC & 535 \\
Transferrin R & CGAAAGGCCTAGAACGTTTG & \\
IMPI F & ATTTGTAACGGTGGACACGA & 409 \\
IMPI R & CGCAAATTGGTATGCATGG & \\
Galiomicin F & CCTCTGATTGCAATGCTGAGTG & 359 \\
Galiomicin R & GCTGCCAAGTTAGTCAACAGG & \\
Gallerimycin F & GAAGATCGCTTTCATAGTCGC & 175 \\
Gallerimycin R & TACTCCTGCAGTTAGCAATGC & \\
\hline
\end{tabular}

${ }^{\mathrm{a}} \mathrm{F}$ indicates a forward primer.

${ }^{\mathrm{b}} \mathrm{R}$ indicates a reverse primer. 
(6 M urea, 30\% (v/v) glycerol, 2\% (w/v) SDS, $50 \mathrm{mM}$ Tri$\mathrm{s}-\mathrm{HCl}, \mathrm{pH} 6.8$ and stored at $-20{ }^{\circ} \mathrm{C}$ ). The first equilibration step was carried out in equilibration buffer containing $2 \%(\mathrm{w} /$ v) DTT and the second equilibration step contained $2.5 \%$ (w/ v) iodoacetamide. The IPG strips were blotted to remove excess liquid and quickly applied to a 10\% SDS-PAGE slab gel in a Biorad protean gel rig. Sealing solution $(1 \times$ running buffer with $0.5 \%(\mathrm{w} / \mathrm{v})$ agarose and $0.002 \%(\mathrm{w} / \mathrm{v})$ bromophenol blue) was melted and allowed to cool before pouring on top of the IPG strip. Running buffer $(5 \times)$ was placed in the internal chamber of the gel rig and gels were electrophoresed overnight at $50 \mathrm{~V}$ at room temperature. Separated proteins were visualised by Coomassie staining.

\subsection{Image acquisition and analysis}

The protein spots of interest on each gel were detected, normalised, edited and manually matched to a reference gel. Proteins separated by $2 \mathrm{D}$ electrophoresis were quantified in terms of their relative volume $(\% \mathrm{Vol})$. The intensity volume of each spot was processed by background subtraction and total spot volume normalization, and the resulting spot volume percentage was used for comparison. Proteins that were up- or downregulated and proteins that appeared or disappeared under one condition or another were selected for analysis with MS.

\subsection{Protein identification by MALDI TOF analysis}

Mass spectrometry of trypsin digested proteins was performed using an Ettan ${ }^{\mathrm{TM}}$ MALDI-TOF spectrometer (Amersham Biosciences, Gmbh, Freiburg, Germany). The resulting mass list from tryptic-digested protein was analysed using ProFound peptide mapping version 4.10.5 developed by Rockefeller University (http://www.unb.br/cbsp/paginiciais/ profound.htm). The taxonomy used to identify tryptic fingerprint was Drosophila and other metazoa with a tolerance mass error of 1.0 Da. Verification of sequences was performed using a BLAST search on the NCBI website (http:// www.ncbi.nlm.nih.gov) to identify conserved domains of protein families.

\subsection{Statistical analysis}

All assays were preformed on three independent occasions. Results are expressed as the mean $\pm \mathrm{SE}$ and were compared by $t$-test using Sigma Stat Statistical analysis Package Version 1.00 (SPSS Inc., Chicago, IL, USA). Differences were considered significant at $p \leq 0.05$.

\section{Results}

\subsection{Sub-lethal infections protect $\mathrm{G}$. mellonella larvae from subsequent lethal infections}

It has previously been established that $G$. mellonella larvae are susceptible to infection with an inoculation dose of $10^{6}$ C. albicans cells/insect [20,22]. In this study, larvae of
G. mellonella were inoculated with different doses $\left(10^{4}, 10^{5}\right.$ or $10^{6}$ ) of $C$. albicans or $S$. cerevisiae cells. The results (Fig. 1A) indicate that inoculation doses of $10^{4}$ or $10^{5}$ cells of $C$. albicans have no effect on the larval survival. An inoculation density of $10^{6}$ C. albicans cells/larva results in $80 \%$ mortality after $48 \mathrm{~h}$ and approximately $95 \%$ mortality after $72 \mathrm{~h}$. In the case where larvae are pre-inoculated with a sublethal dose $\left(10^{4}\right.$ or $\left.10^{5}\right)$ of $C$. albicans and given a subsequent lethal dose $\left(10^{6}\right)$ of this yeast after $24 \mathrm{~h}$ there is little or no death over the following $72 \mathrm{~h}$ (Fig. 1A). Inoculation of the lethal dose of $C$. albicans $48 \mathrm{~h}$ after administration of the non-lethal dose results in larval death regardless of whether
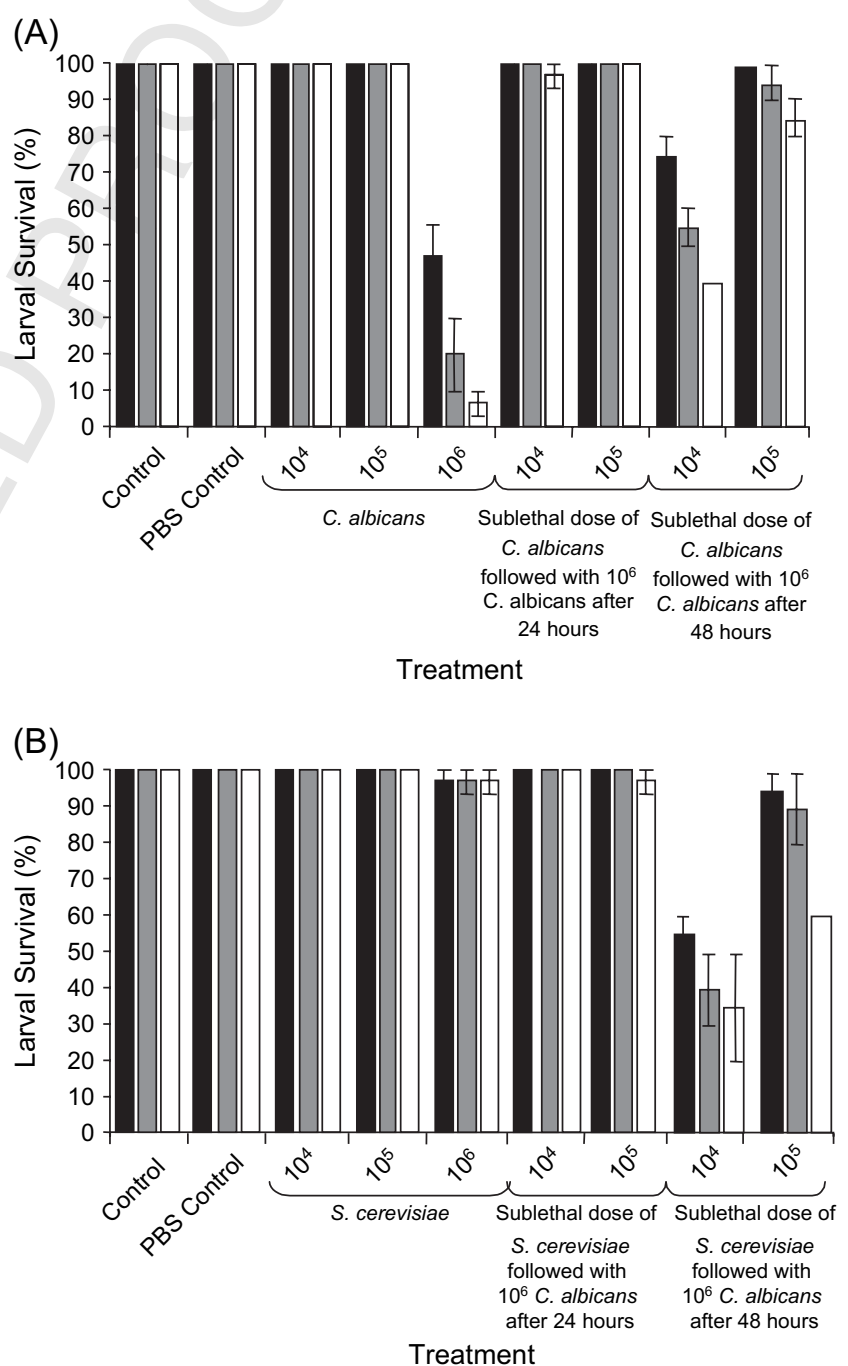

Fig. 1. Viability assay in G. mellonella larvae inoculated with yeast isolates. (A) Percentage survival of $G$. mellonella larvae following inoculation with C. albicans MEN at 24 (black), 48 (gray) and $72 \mathrm{~h}$ (white). Larvae were pre-inoculated with sub-lethal dose of $C$. albicans MEN and followed with a lethal dose of $10^{6}$ yeast cells of $C$. albicans MEN after $24 \mathrm{~h}$ or $48 \mathrm{~h}$ later and observed for a further 72 h. (B) Percentage survival of G. mellonella larvae following inoculation with S. cerevisiae YJM128 after 24 (black), 48 (gray) and $72 \mathrm{~h}$ (white) is shown. Larvae were pre-inoculated with sub-lethal dose of $S$. cerevisiae YJM128 and followed with a lethal dose of $10^{6}$ yeast cells of $C$. albicans MEN after $24 \mathrm{~h}$ or $48 \mathrm{~h}$ and observed for a further $72 \mathrm{~h}$. All values represent the mean \pm standard error of three independent experiments. 
the $10^{4}$ or $10^{5}$ C. albicans inoculum was used. It is noteworthy that the greatest kill is evident in those larvae that were given the former dose.

Inoculation of $G$. mellonella larvae with $S$. cerevisiae at densities of $10^{4}, 10^{5}$ or $10^{6}$ /insect results in low levels of larval death (about 5\%) at the higher inoculation dose over the test period (Fig. 1B). Pre-inoculation of larvae with a sub-lethal dose $\left(10^{4}\right.$ or $10^{5}$ cells) of $S$. cerevisiae $24 \mathrm{~h}$ prior to inoculation with a lethal dose of $C$. albicans cells $\left(10^{6}\right)$ offers almost complete protection to larvae (Fig. 1B). Introduction of the lethal dose $48 \mathrm{~h}$ after the initial non-lethal $S$. cerevisiae challenge results in an increased larval mortality particularly when the $10^{4}$ yeast cells/insect inoculum was employed.

Laminarin, a polymer of $\beta-1,3$ glucan from Laminaria digitata, and mannan, from $S$. cerevisiae, both at a concentration of $60 \mu \mathrm{g} / 20 \mu \mathrm{l}$ were injected into the larvae. Neither of these components has any effect on larval survival over a period of $72 \mathrm{~h}$ (Fig. 2). When larvae were inoculated with laminarin and given a subsequent lethal dose of $C$. albicans $24 \mathrm{~h}$ later there was no larval death. In the case of larvae inoculated with mannan approximately $95 \%$ of larvae survived the challenge over the course of the experiment.

The results presented here indicate that $G$. mellonella larvae can be protected from a lethal infection $\left(10^{6} \mathrm{C}\right.$. albicans cells $)$ if pre-inoculated with a sub-lethal dose $\left(10^{4}\right.$ or $\left.10^{5}\right)$ C. albicans or S. cerevisiae cells or pre-challenged with polymers associated with the fungal cell wall.

\subsection{Gene expression of proteins involved in an immune response}

During an immune reaction to microbes, the up-regulation of proteins of the immune system is observed in Drosophila [10]. In this study, gene expression was monitored and it was demonstrated that certain antimicrobial peptides (AMPs) were up-regulated depending on the type of microbe infecting the insect [10]. As noted previously here, protection against

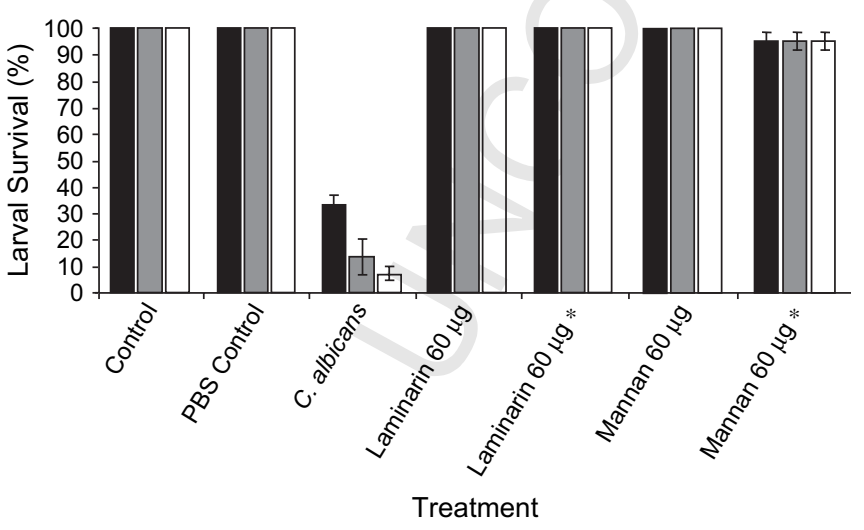

Fig. 2. Viability of G. mellonella larvae inoculated with fungal cell wall components. The percentage survival of larvae challenged with $C$. albicans, laminarin and mannan after 24 (black), 48 (gray) and $72 \mathrm{~h}$ (white). Larvae were pre-inoculated with laminarin and mannan at $t=0$ and $(*)$ followed with a lethal dose of $C$. albicans MEN after $24 \mathrm{~h}$. All values represent the mean \pm standard error of three independent experiments. a lethal infection by $C$. albicans can be induced within challenged larvae that were pre-inoculated with sub-lethal doses of $C$. albicans or S. cerevisiae, or yeast cell wall constituents. Here we sought to measure the expression of genes coding for proteins and peptides involved in this protective immune response within larvae following infection with a sub-lethal dose of viable yeast cells or a major cell wall component of fungi. Larvae were inoculated with $10^{5}$ cells of $C$. albicans or S. cerevisiae, laminarin $(60 \mu \mathrm{g} / 20 \mu \mathrm{l})$ or $20 \mu \mathrm{l}$ PBS (termed 'injured' larvae). RNA was extracted from whole larvae over $48 \mathrm{~h}$ and cDNA was generated. The genes that were examined coded for galiomicin, a defensin identified in G. mellonella [13], a cysteine-rich antifungal peptide gallerimycin [25], transferrin, an iron binding protein and an inducible metalloproteinase inhibitor (IMPI) from G. mellonella [12] (Fig. 3).

In the case of galiomicin, injury to the larvae induced relative expression of $40 \%$ after $1 \mathrm{~h}$ rising to an expression level of 50\% at $48 \mathrm{~h}$ with the highest level of expression being observed at $24 \mathrm{~h}(58 \%)$ (Fig. 4A). When a sub-lethal dose of $C$. albicans or $S$. cerevisiae was inoculated into the larvae the transcription level of this defensin was increased with the initial expression rates of $60 \%$ or $80 \%$, respectively, at $1 \mathrm{~h}$. Eventually, the highest expression was seen at 8 and $24 \mathrm{~h}$, ranging from $78 \%$ to $94 \%$ for larvae inoculated with $C$. albicans. Larvae inoculated with $S$. cerevisiae showed maximum expression at $8 \mathrm{~h}$ (Fig. 4A). Larvae inoculated with laminarin showed a high transcription rate (73\%) for galiomicin at $24 \mathrm{~h}$.

Larvae subjected to injury (PBS) showed expression levels for gallerimycin not exceeding $30 \%$ over $48 \mathrm{~h}$ (Fig. 4B). C. albicans challenged larvae showed a dramatic increase in expression of gallerimycin transcript to reach a level of $65 \%$ at $4 \mathrm{~h}$. This was further increased by another $11 \%$ at 8 h. S. cerevisiae inoculated insects did not show an increase as dramatic as in gallerimycin expression until $8 \mathrm{~h}$ where it was the highest expression in this series at $100 \%$. This expression level decreased to $35 \%$ at $24 \mathrm{~h}$. Laminarin had similar effects on the expression of gallerimycin as an $\mathrm{S}$. cerevisiae inoculation at $1 \mathrm{~h}$. Expression increased to $71 \%$ at $4 \mathrm{~h}$ and rose to $81 \%$ at $24 \mathrm{~h}$.

From Fig. 4C it can be seen that the expression of transferrin RNA in 'injured' insects was $26 \%$ at $1 \mathrm{~h}$ and increased to a maximum of $48 \%$ at $8 \mathrm{~h}$. Both C. albicans and S. cerevisiae

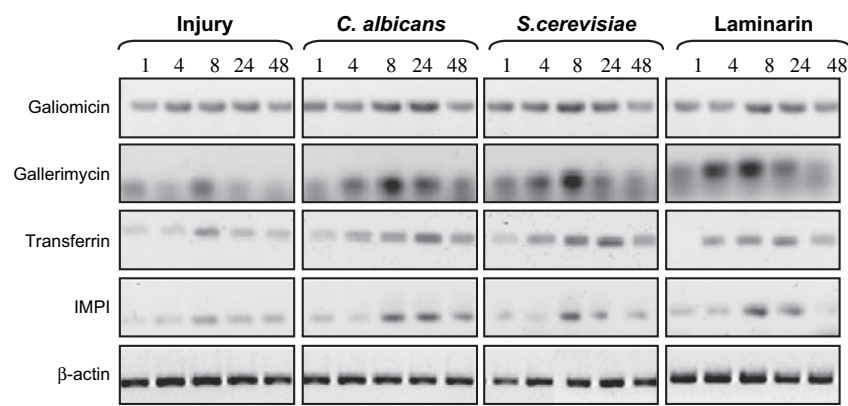

Fig. 3. RT PCR analysis of $G$. mellonella cDNA from whole larvae on a $1 \%$ agarose gel. Larvae were given a mock inoculation or infected with $C$. albicans MEN, S. cerevisiae YJM128 and laminarin at 1, 2, 4, 8, 24 and $48 \mathrm{~h}$. Three independent RNA extractions were carried out and pooled. PCR was performed using primers for galiomicin, gallerimycin, transferrin, IMPI and $\beta$ actin (housekeeping gene) on cDNA. 
(A)

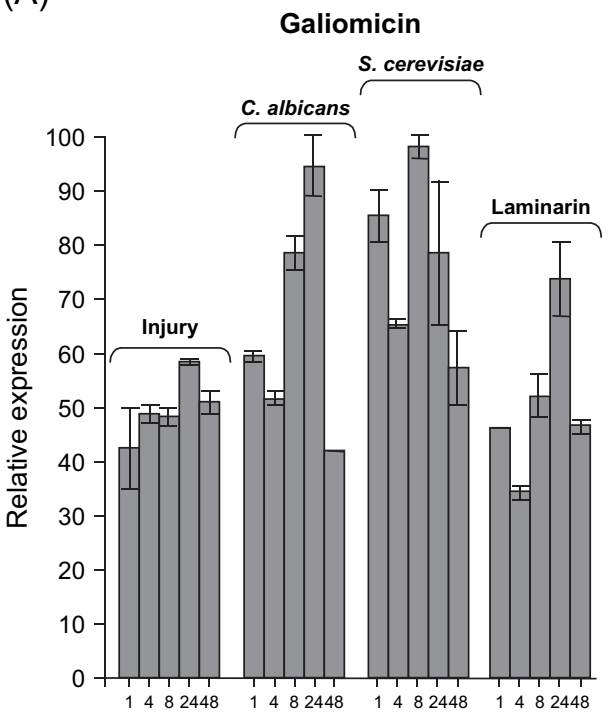

(C)

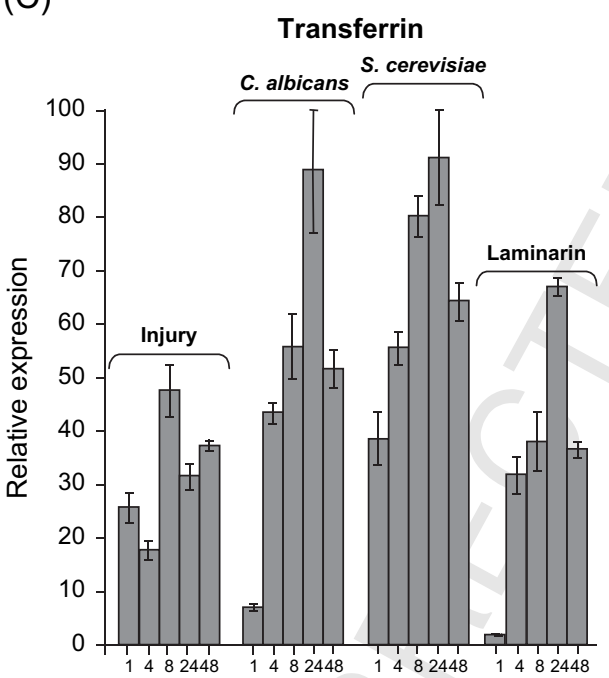

(B)

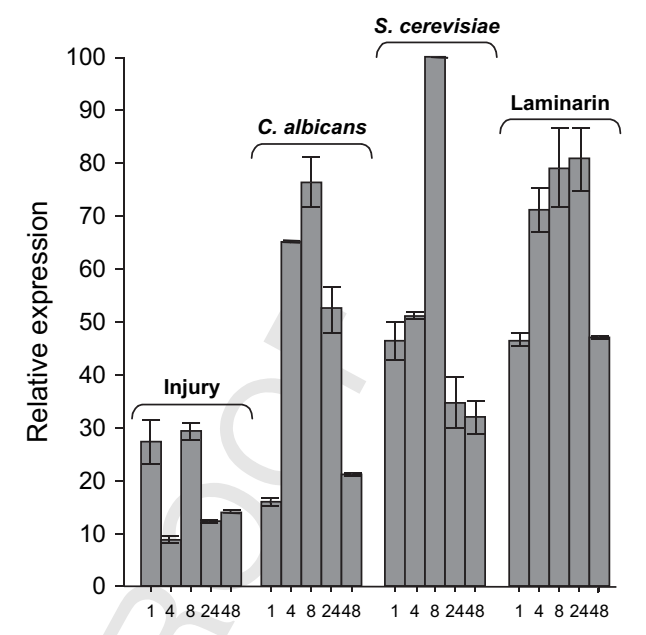

(D)

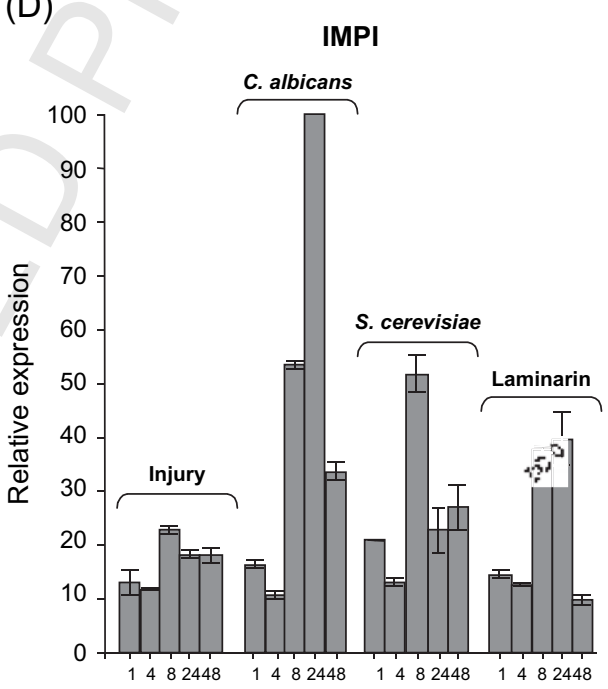
of expression to the yeast infected larvae, the highest expression level being $67 \%$ at $24 \mathrm{~h}$.

Mock infection of larvae did not have a significant effect on the expression level of IMPI with expression level being approximately $20 \%$ over $48 \mathrm{~h}$ (Fig. 4D). After $8 \mathrm{~h}$ in C. albicans challenged larvae, IMPI expression level is $50 \%$ and rises to $100 \%$ at $24 \mathrm{~h}$. S. cerevisiae infected larvae showed expression of IMPI at $8 \mathrm{~h}$ at $52 \%$ while laminarin challenged larvae demonstrated expression levels of $38 \%$ and $40 \%$ at 8 and $24 \mathrm{~h}$, respectively (Fig. 4D).

The results presented here indicate that prior infection with a sub-lethal dose of yeast or fungal cell wall components leads to elevated expression of genes coding for key antimicrobial peptides $24 \mathrm{~h}$ post-challenge.
To investigate the changes in haemolymph protein composi-

\section{3. $2 \mathrm{D}$ gel electrophoresis and MALDI TOF \\ analysis of haemolymph of challenged larvae} tion of larval haemolymph due to infection by fungal pathogens, 2D gel electrophoresis was employed and relevant proteins were excised and digested with trypsin for MALDI TOF analysis. Control haemolymph was obtained from larvae that had received a PBS injection. From the ImageMaster 2D analysis of the gels 13 spots were analysed for their altered expression. Proteins were identified through ProFound peptide lymph of G. mellonella with a wide range of functions (Table 2).

Several proteins have already been identified and assigned functions in the insect's immune response to infection [15]. RE07451p (spot number 11) contains cyclophilin domains and is a member of the peptidyl-prolyl cis-trans isomerase mapping. Several proteins were identified within the haemo-
557

558

559

560

561

562

563

564

565

566

567 
Table 2

Summary of proteins identified on Coomassie stained 2D gels of challenged larvae haemolymph

\begin{tabular}{|c|c|c|c|c|c|c|c|}
\hline Function & Identified proteins & $\begin{array}{l}\text { Spot } \\
\text { number }\end{array}$ & $\begin{array}{l}\text { NCBI accession } \\
\text { number }\end{array}$ & $\begin{array}{l}\text { \%Protein } \\
\text { coverage }\end{array}$ & $Z$ score & \multicolumn{2}{|c|}{ Fold expression level } \\
\hline Carbohydrate metabolism & Phosphoglycerate kinase & 1 & AAL58083.1 & 24 & 1.07 & -0.8 & -0.02 \\
\hline \multirow{2}{*}{$\begin{array}{l}\text { Nucleoside triphosphate } \\
\text { synthesis/signal transduction }\end{array}$} & CG8362-PA & 3 & NP_649926.2 & & 1.19 & +0.05 & +0.06 \\
\hline & Similar to CG10026-PA & 4 & XP_391912.1 & 23 & 1.02 & -0.27 & +0.06 \\
\hline Unknown & GH25284p & 7 & AAL28331.1 & 16 & 1.71 & +2.03 & -0.07 \\
\hline Blood clotting & ENSANGP00000019647 & 8 & XP_318536.1 & 16 & 0.54 & +8.19 & +0.05 \\
\hline Eukaryotic protein B9 & Hypothetical protein CBG11067 & 9 & CAE65900.1 & 29 & 0.42 & +5.52 & +0.11 \\
\hline Unknown & $27 \mathrm{k}$ hemolymph protein & 10 & CAE02611.1 & 34 & 0.89 & +7.02 & -0.21 \\
\hline PPIase activity & RE07451p & 11 & AAL48597.1 & 19 & 0.24 & +1.20 & +1.79 \\
\hline
\end{tabular}

family (PPIase) which functions in the catalysing and isomerising of the $\mathrm{N}$ terminal peptide bonds to proline residues from polypeptides [27]. In larvae challenged with $C$. albicans there was an increase by 1.2 -fold in the expression of this protein.

Apolipophorin precursor (spot number 13) was identified in the haemolymph of larvae challenged with $C$. albicans or $S$. cerevisiae. This protein has been shown to increase and stimulate the immune response and its ability to stimulate an immune response is associated with its lipid binding capabilities [13]. Here there was a 5-fold decrease in the precursor form of this protein in $C$. albicans challenged larvae whichwould suggest that the protein's active form was increased.

Another protein of interest was ENSANGP00000019647 (spot number 8). This protein contains fibrinogen-related domains involved in blood clotting which increases in Biomphalaria glabrata upon infection and is thought to be a lectin involved in the innate immune response [28]. From the 2D gels of larvae infected with $C$. albicans there is an 8-fold increase in the expression of this protein (Table 2).
A $27 \mathrm{kDa}$ protein (spot number 10) of G. mellonella was identified, although no function is known for this protein there is a 7-fold increase in $C$. albicans challenged larvae. Other proteins identified across the three different haemolymph samples range from those involved with kinase activity, carbohydrate metabolism, serine protease and elongation factors (Table 2).

Induction of new protein spots was observed in haemolymph protein gels from larvae challenged with $C$. albicans and S. cerevisiae (Fig. 5 and Table 3). Hemolin (spot number 14), a member of the immunoglobulin superfamily, was induced by both yeast isolates within $G$. mellonella larvae. A detoxifying enzyme, Glutathione S-transferase D1 (spot number 21 ), was observed to be induced within the $C$. albicans challenged larvae but was not observed in $S$. cerevisiae challenged larvae. Conversely, Peritrophin-48 precursor (spot number 20) was observed to be induced in $S$. cerevisiae inoculated larvae and this plays an important role in digestion, protection of the midgut from mechanical damage and invasion by microorganisms [29] (Table 3).
(A)

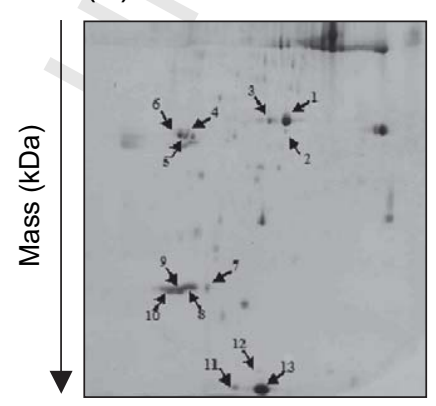

(B)

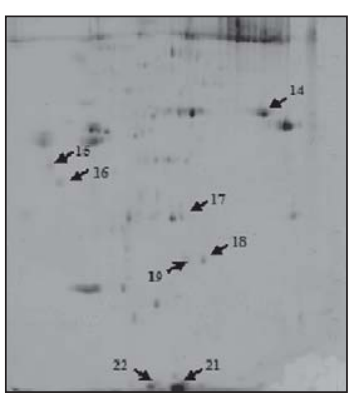

(C)

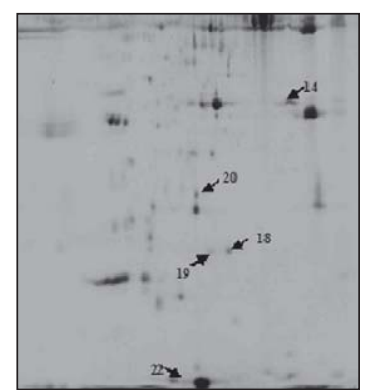


Table 3

Summary of induced proteins identified on Coomassie stained 2D gels of challenged larvae haemolymph

\begin{tabular}{|c|c|c|c|c|c|}
\hline Function & Identified proteins & $\begin{array}{l}\text { Spot } \\
\text { number }\end{array}$ & $\begin{array}{l}\text { NCBI accession } \\
\text { number }\end{array}$ & $\begin{array}{l}\% \text { Protein } \\
\text { coverage }\end{array}$ & $Z$ score \\
\hline Lipid binding protein & $\begin{array}{l}\text { Insect immune } \\
\text { protein hemolin }\end{array}$ & 14 & $1 \mathrm{BIH} \mid \mathrm{B}$ & 12 & 2.11 \\
\hline Unknown & CG33251-PA & 15 & AAS65385 & 7 & 1.10 \\
\hline Peptidase & GH14075p & 16 & AAL28246 & 12 & 1.21 \\
\hline $\begin{array}{l}\text { Carbohydrate transport } \\
\text { and metabolism/signal } \\
\text { transduction } \\
\text { mechanisms }\end{array}$ & $\begin{array}{l}\text { Similar to hypothetical } \\
\text { protein C730031G17 }\end{array}$ & 17 & N/A & 9 & 0.29 \\
\hline Cell differentiation & GH15157p & 18 & AAM50645 & 13 & 0.52 \\
\hline Initiation factor & ENSANGP00000019638 & 19 & EAA08959 & 16 & 1.75 \\
\hline Chitin binding protein & Peritrophin-48 precursor & 20 & P91745 & 6 & 0.86 \\
\hline Detoxifying enzyme & Glutathione S-transferase D1 & 21 & AAR23015 & 11 & 0.88 \\
\hline Unknown & GH07105p & 22 & AAL25286 & 20 & 0.55 \\
\hline
\end{tabular}

\section{Discussion}

The results presented in this study indicate that the challenge of G. mellonella larvae with sub-lethal doses of C. albicans or $S$. cerevisiae protects the insects from a challenge $24 \mathrm{~h}$ later with a lethal dose of $C$. albicans. This protection can also be induced by inoculating the insects with fungal cell wall constituents $24 \mathrm{~h}$ prior to the administration of the lethal dose. Analysis of the expression of genes coding for peptides associated with the insect immune response to infection reveals elevated levels of expression at 8 and $24 \mathrm{~h}$. Two-dimensional SDS-PAGE and MS analyses of haemolymph samples from larvae inoculated with sub-lethal doses of $C$. albicans or $S$. cerevisiae reveal increased expression of proteins associated with the immune response to infection. In addition, induced proteins were present in the yeast challenged larvae but were not present in the uninfected larvae.

Exposure of the invertebrate immune system to sub-lethal doses of pathogens has been shown to protect against subsequent lethal doses. Analysis of the expression of genes coding for immune related proteins and peptides and examination of the haemolymph profile of $G$. mellonella larvae that had received a protective inoculum were performed to establish whether there was a correlation with increased larval survival following sub-lethal infections. Genes coding for several AMPs increased in expression after challenging Drosophila with a range of microorganisms with the increase in gene expression being evident from 3 to $24 \mathrm{~h}$ post-challenge [10]. The work presented here demonstrates that when larvae are inoculated with non-lethal doses of yeast cells or a major fungal cell wall component there is an increase in the expression of genes coding for proteins involved in the humoral immune response. Previous studies involving the four genes examined in this study have demonstrated that naive insects have a lower expression level when compared to infected insects [10,11]. Galiomicin has been shown to be induced in larvae infected with Escherichia coli and to have antifungal as well as antibacterial activities [24]. Here the expression of galiomicin is higher in infected larvae when compared to mock-inoculated larvae with the highest expression being at 8 and $24 \mathrm{~h}$. Gallerimycin, a cysteine-rich antimicrobial peptide, has been shown to increase in expression when larvae were inoculated with LPS [25] and here the expression in larvae challenged with both yeast isolates and laminarin showed elevated expression from 4 to $24 \mathrm{~h}$. It has been demonstrated previously that transferrin in Drosophila melanogaster is up-regulated upon infection with bacteria [11] and this was also observed here in larvae challenged with sub-lethal doses of $C$. albicans and $S$. cerevisiae with the highest transcript level being recorded $24 \mathrm{~h}$ postinoculation. The first metalloproteinase inhibitor (IMPI) characterised in invertebrates was purified from $G$. mellonella and may have a role in protecting the larvae against fungal infections. Recent work indicates that IMPI is up-regulated in larvae upon exposure to LPS [12]. In larvae challenged with $C$. albicans the increase in gene expression of IMPI at the $24 \mathrm{~h}$ time point was large.

Analysis of protein expression levels revealed increased expression of a number of proteins implicated in the immune response in larvae challenged with $C$. albicans. The $2 \mathrm{D}$ analysis of gels resulted in 22 spots being identified from haemolymph profiles through MALDI TOF analysis. Of these 22 proteins, 13 spots were common to the control haemolymph sample. Of these common spots several immune related proteins showed increased expression within the infected larvae. Those proteins displaying a dramatic increase in expression were proteins which contained domains similar to proteins involved in blood clotting (spot number 8), a protein involved in PPIase activity (spot number 11) that has been implicated in aiding the folding of newly synthesised proteins [15], a $27 \mathrm{kDa}$ haemolymph protein (spot number 10) of unknown function and eukaryotic protein B9 (spot number 9). A decrease in the expression of Apolipophorin III precursor was observed, Apolipophorin III has been implicated in the immune response in insects [28] and it is possible that the precursor decreases because it is being used to synthesise functional protein.

Hemolin (spot number 14) was induced in challenged larvae and is important because it belongs to the Ig superfamily and has been shown to be a pattern recognition receptor in insects [30]. A GST (spot number 21) was observed in larvae inoculated with a sub-lethal dose of $C$. albicans. GSTs are well-known detoxifying enzymes that act against a range of harmful substances such as reactive oxidative species. Peritrophin- 48 precursor (spot 
number 20) was present in larvae inoculated with $S$. cerevisiae and this protein has a role in protection against infection. It is evident from the 2D analysis of larval haemolymph that key proteins involved in pathogen recognition and defence are increased in expression when larvae are challenged with sub-lethal doses of $C$. albicans or S. cerevisiae.

Once a pathogen enters the insect's haemocoel, haemocytes can either engulf the invading microbe or, if it is too large, encapsulate and immobilise it. The production of AMPs, a key component of the humoral response, serves to kill pathogens that have escaped or withstood the cellular immune response. The results presented here indicate that maximum expression of selected antimicrobial peptides occurs 8 or $24 \mathrm{~h}$ after administration of the sub-lethal dose of yeast cells or cell wall component. This work indicates that prior exposure to a sublethal dose of a pathogen primes the $G$. mellonella immune system and allows the larvae to withstand a subsequent lethal yeast infection. This effect is mediated by the production of elevated levels of AMPs which protect the insect from the second exposure to the pathogen. Protracted production of AMPs would not only ensure that minor infections are controlled but also that the insect is protected against a larger, potentially lethal secondary infection within a short period of time $(24 \mathrm{~h})$.

\section{Uncited reference}

\section{[26]}

\section{Acknowledgements}

This work was supported by funds from the Higher Education Authority of Ireland through the Programme for Research in Third Level Institutes III (2002-2007).

\section{References}

[1] H.G. Bowman, D. Hultmark, Cell-free immunity in insects, Annu. Rev. Microbiol. 41 (1987) 103-126.

[2] P. Vilmos, E. Kurucz, Insect immunity: evolutionary roots of the mammalian innate immune system, Immunol. Lett. 62 (1998) 59-66.

[3] M.D. Lavine, M.R. Strand, Insect hemocytes and their role in immunity, Insect Biochem. Mol. Biol. 32 (10) (2002) 1295-1309.

[4] C. Lowenberger, Innate immune response of Aedes aegypti, Insect Biochem. Mol. Biol. 31 (3) (2001) 219-229.

[5] P. Bulet, C. Hetru, J.L. Dimarcq, D. Hoffmann, Antimicrobial peptides in insects; structure and function, Dev. Comp. Immunol. 23 (4-5) (1999) 329-344.

[6] V. Leclerc, J.M. Reichhart, The immune response of Drosophila melanogaster, Immunol. Rev. 198 (2004) 59-71.

[7] N.A. Ratcliffe, Invertebrate immunity - a primer for the non-specialist, Immunol. Lett. 10 (5) (1985) 253-270.

[8] E. Vierstraete, P. Verleyen, G. Baggerman, W. D'Hertog, G. Van den Bergh, L. Arckens, A. De Loof, L.A. Schoofs, Proteomic approach for the analysis of instantly released wound and immune proteins in Drosophila melanogaster hemolymph, Proc. Natl. Acad. Sci. U.S.A. 101 (2) (2004) 470-475.

[9] H. Heine, E. Lien, Toll-like receptors and their function in innate and adaptive immunity, Int. Arch. Allergy Immunol. 130 (3) (2003) 180-192.

[10] B. Lemaitre, J.M. Reichhart, J.A. Hoffmann, Drosophila host defense: differential induction of antimicrobial peptide genes after infection by various classes of microorganisms, Proc. Natl. Acad. Sci. U.S.A. 94 (26) (1997) 1461-1469.

[11] T. Yoshiga, T. Georgieva, B.C. Dunkov, N. Harizanova, K. Ralchev, J.H. Law, Drosophila melanogaster transferrin. Cloning, deduced protein sequence, expression during the life cycle, gene localization and upregulation on bacterial infection, Eur. J. Biochem. 260 (2) (1999) 414-420.

[12] A. Clermont, M. Wedde, V. Seitz, L. Podsiadlowski, D. Lenze, M. Hummel, A. Vilcinskas, Cloning and expression of an inhibitor of microbial metalloproteinases from insects contributing to innate immunity, Biochem. J. 382 (1) (2004) 315-322.

[13] M. Niere, M. Dettloff, T. Maier, M. Ziegler, A. Wiesner, Insect immune activation by Apolipophorin III is correlated with the lipid-binding properties of this protein, Biochemistry 40 (30) (2001) 11502-11508.

[14] L. Shi, S.M. Paskewitz, Identification and molecular characterization of two immune-responsive chitinase-like proteins from Anopheles gambiae, Insect Mol. Biol. 3 (4) (2004) 387-398.

[15] M. Guedes de, R. Vitorino, K. Tomer, M.R. Domingues, A.J. Correia, F. Amado, P. Domingues, Drosophila melanogaster larval hemolymph protein mapping, Biochem. Biophys. Res. Commun. 312 (3) (2003) 545-554.

[16] F. Levy, D. Rabel, M. Charlet, P. Bulet, J.A. Hoffmann, L. Ehret-Sabatier, Peptidomic and proteomic analyses of the systemic immune response of Drosophila, Biochimie. 86 (9-10) (2004) 607-616.

[17] E. Vierstraete, A. Cerstiaens, G. Baggerman, G. Van den Bergh, A. De Loof, L. Schoofs, Proteomics in Drosophila melanogaster: first 2D database of larval hemolymph proteins, Biochem. Biophys. Res. Commun. 304 (4) (2003) 831-838.

[18] K. Kavanagh, E.P. Reeves, Exploiting the potential of insects for the in vivo pathogenicity testing of microbial pathogens, FEMS Microbiol. Rev. 28 (2004) 101-112.

[19] B.E. Mansfield, M.S. Dionne, D.S. Schneider, N.E. Freitag, Exploration of host-pathogen interactions using Listeria monocytogenes and Drosophila melanogaster, Cell. Microbiol. 5 (12) (2003) 901-911.

[20] G. Cotter, S. Doyle, K. Kavanagh, Development of an insect model for the in vivo pathogenicity testing of yeasts, FEMS Immunol. Med. Microbiol. 27 (2000) 163-169.

[21] N. Boulanger, L. Ehret-Sabatier, R. Brun, D. Zachary, P. Bulet, J.L. Imler, Immune response of Drosophila melanogaster to infection with the flagellate parasite Crithidia spp. Insect Biochem. Mol. Biol. 31 (2) (2001) 129-137.

[22] M. Brennan, D.Y. Thomas, M. Whiteway, K. Kavanagh, Correlation between virulence of Candida albicans mutants in mice and Galleria mellonella larvae, FEMS Immunol. Med. Microbiol. 34 (2) (2002) 153-157.

[23] G. Jander, L.G. Rahme, F.M. Ausubel, Positive correlation between virulence of Pseudomonas aeruginosa mutants in mice and insects, J. Bacteriol. 182 (13) (2000) 3843-3845.

[24] Y.S. Lee, E.K. Yun, W.S. Jang, I. Kim, J.H. Lee, S.Y. Park, K.S. Ryu, S.J. Seo, C.H. Kim, I.H. Lee, Purification, cDNA cloning and expression of an insect defensin from the great wax moth, Galleria mellonella, Insect Mol. Biol. 13 (1) (2004) 65-72.

[25] B. Schuhmann, V. Seitz, A. Vilcinskas, L. Podsiadlowski, Cloning and expression of gallerimycin, an antifungal peptide expressed in immune response of greater wax moth larvae, Galleria mellonella, Arch. Insect Biochem. Physiol. 53 (3) (2003) 125-133.

[26] Y. Wang, P. Zhang, H. Fujii, Y. Banno, K. Yamamoto, Y. Aso, Proteomic studies of lipopolysaccharide-induced polypeptides in the silkworm, Bombyx mori, Biosci. Biotechnol. Biochem. 68 (8) (2004) 1821-1823.

[27] P.E. Shaw, Peptidyl-prolyl isomerases: a new twist to transcription, EMBO Rep. 3 (6) (2002) 521-526.

[28] C.M. Adema, L.A. Hertel, R.D. Miller, E.S. Loker, A family of fibrinogen-related proteins that precipitates parasite-derived molecules is produced by an invertebrate after infection, Proc. Natl. Acad. Sci. U.S.A. 94 (16) (1997) 8691-8696.

[29] T. Vuocolo, C.H. Eisemann, R.D. Pearson, P. Willadsen, R.L. Tellam, Identification and molecular characterisation of a peritrophin gene, peritrophin-48, from the myiasis fly Chrysomya bezziana, Insect Biochem. Mol. Biol. 31 (9) (2001) 919-932.

[30] S. Daffre, I. Faye, Lipopolysaccharide interaction with hemolin, an insect member of the Ig-superfamily, FEBS Lett. 408 (2) (1997) 127-130. 